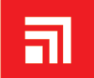 \\ CHITKARA \\ Journal of Chemistry, Environmental Sciences and its Applications \\ Journal homepage: https://jce.chitkara.edu.in/
}

\section{Cyclopentadienyl System: Solving the Secular Determinant, $\pi$ Energy, Delocalization Energy, Wave Functions, Electron Density and Charge Density}

\author{
Vikram R. Jadhav' ${ }^{1}$ D, Y.R. Baste ${ }^{2}$ Jamdhade Madhuri $^{3}$ and Wadhawane Pooja ${ }^{4}$ \\ ${ }^{1,3,4}$ K.K. Wagh Art's, Commerce and Science College, Pimpalgaon Baswant, Maharashtra-422209, India \\ ${ }^{2}$ K. S. K. W. Arts, Science and Commerce College, Uttamnagar, Cidco, Nashik, Maharashtra-422010, India \\ 'mevikramjadhav@gmail.com (Corresponding Author) \\ ²yogeshwarbaste@yahoo.co.in \\ sjamdhademadhuri6@gmail.com \\ ‘pujawadhawane98@gmail.com
}

\section{ARTICLE INFORMATION}

Received: October 04, 2019

Revised: December 18, 2019

Accepted: January 06, 2020

Published Online: March 10, 2020

Keywords:

Charge density, Cyclopentadienyl system,

Electron density, Hückel theory, Secular equation

DOI: $10.15415 /$ jce. 2020.62002

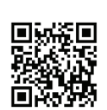

\begin{abstract}
In this study, characteristics of Hückel strategy, were abused to acquire some significant outcomes, through a theoretical technique with which it is conceivable to get secular equations, $\pi$ energy, wave functions, electron density and charge density, as an account of cyclopentadienyl system i.e. $\mathrm{C}_{5} \mathrm{H}_{5}^{+}$ (cation), $\mathrm{C}_{5} \mathrm{H}_{5}^{-}$(anion), and $\mathrm{C}_{5} \mathrm{H}_{5}{ }^{-}$(radical) and permitting the expression of delocalization energy of conjugated cyclopentadienyl ring framework. Here, it was presented the secular determinant of the Hückel technique and applied to cyclopentadienyl system framework so as to communicate their orbital energies of cyclopentadienyl system, also to communicate its electron and charge density in terms of stable configuration of a system. It is settled by the Hückel strategy and applied by the assumptions for nearby comparability such as coulomb integrals, exchange integrals and overlap integrals. This simple way hypothetical strategy will allow to graduate and post graduate understudies to understanding the investigation of stable configuration, electron and charge density and also other parameters.
\end{abstract}

\section{Introduction}

The conjugated aromatic cyclic molecules such as benzene, cyclobutene, cyclopentadiene, naphthalene, etc. were investigated by Hückel in 1931(Puri, Sharma, Pathania \& Kaur, 2009). This method further extended by C. Coulson, H. C. Longuet Higgins and R. Hoffmann (Puri, Sharma, Pathania \& Kaur, 2009). In the fully conjugated system, there is present of alternate double bonds, the molecule considers as planer. In the $\mathrm{n}^{\text {th }}$ number of carbon atoms in a molecule, shows $\mathrm{sp}^{2}$ hybridization (planer), $2 \mathrm{p}_{\mathrm{z}}$ orbital involved in the hybridization, sigma bond is formed when an axial overlapping between the half-filled atomic orbitals and pi bond is formed by the lateral or side wise overlapping of a half-filled atomic orbitals. Here each $2 \mathrm{p}_{\mathrm{z}}$ orbital is perpendicular to the molecular plane. According to the linear combination of molecular orbital approximation (Puri, Sharma, Pathania \& Kaur, 2009) (LCAO), the wave function of molecular orbital is written as

$$
\Psi_{i}=\sum_{j=1}^{n} C_{i j} \Phi_{j}
$$

Where, $\Phi_{j}=2 p_{z}$ orbital of $j^{\text {th }}$ carbon atoms.

$\mathrm{n}=$ number of molecular orbitals.

$\mathrm{C}_{\mathrm{i}, \mathrm{j}}=$ coefficients of $\mathrm{i}$ and $\mathrm{j}$ values

$\mathrm{i}=1,2,3 \ldots \ldots \ldots \ldots \mathrm{n}$

The Hückel molecular orbital theory of conjugate cyclic molecules is similar to the molecular orbital theory of homonuclear diatomic (Freeman, Tilley, Liable-Sands \& Rheingold, 1996). In the Hückel molecular orbital theory (Freeman, 1980; Yates, 2012), the basic functions are $2 \mathrm{p}_{\mathrm{z}}$ atomic orbitals, whereas in the $\mathrm{H}_{2}$ the basic functions are of the $1 s$ atomic orbitals. Hückel made the following assumptions as, Coulomb integral, exchange integral and overlap integral (Puri, Sharma, Pathania \& Kaur, 2009). All overlap integrals are zero, coulomb integral $(\alpha)$, refers to the energy of an electron in the $2 \mathrm{p}_{\mathrm{z}}$ orbital on the $\mathrm{i}^{\text {th }}$ carbon atom. The exchange or resonance integral represents the energy of interaction of two atomic orbitals. Additional information regarding the Hückel molecular orbital theory is given in an elsewhere (Puri, Sharma, Pathania \& Kaur, 2009). To be aromatic, a molecule must be cyclic and planer and it must have cyclic electron cloud $\pi$, it must satisfy 
Hückel rule $(4 n+2) \pi$ electrons. However, the number of $p$ orbitals participating in the pi system does not necessarily have to be equal to the number of pi electrons (Slee \& Macdougall, 2019). Therefore, anions, cations, and radicals can also be aromatic and the Hückel rule can also be applied accordingly.

Cyclopentadienyl cation is formed from cyclopentadiene as shown in Figure 5, when the hydride anion is removed from $\mathrm{sp}^{3}$ hybridised carbon atom (Jadhav, 2018) in the ring framework, to achieved $\mathrm{sp}^{2}$ carbon atom, so the cyclic cyclopentadienyl cation (Chalyavi et al., 2013) is planar and a cyclic $\pi$ electron cloud as shown in Figure 2. However, it does not obey Hückel rule $(4 \pi)$ electrons. Therefore, it is antiaromatic.

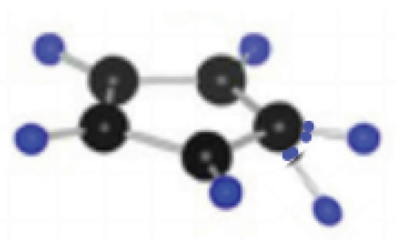

Figure 1: Cyclopentadiene.

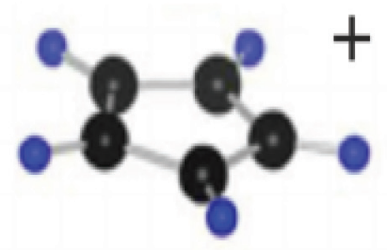

Figure 2: Cyclopentadienyl cation $\left[\mathrm{C}_{5} \mathrm{H}_{5}\right]^{+}$.

The abstraction of a hydrogen atom from the carbon of the $\mathrm{sp}^{3}$ hybrid ring produces the cyclopentadienyl radical as shown in Figure 5. The carbon hybridisation is transformed into $\mathrm{sp}^{2}$. Like the cyclopentadienyl cation, the cyclopentadienyl radical does not conform to Hückel rule, since it has five $\pi$ electrons. Therefore, it is not aromatic.

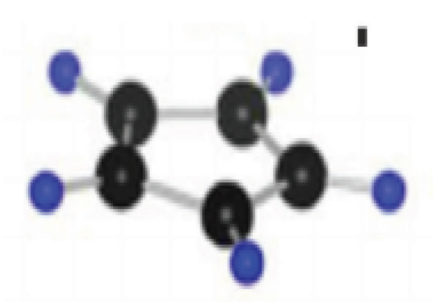

Figure 3: Cyclopentadienyl radical $\left[\mathrm{C}_{5} \mathrm{H}_{5}\right]$.
The abstraction of a proton from the $\mathrm{sp}^{3}$ hybrid carbon (Jadhav, 2018) ring produces the cyclopentadienyl anion (Breton, 1997) as shown as Figure 5. The carbon hybridisation also changed in $\mathrm{sp}^{2}$. The cyclic cyclopentadienyl anion is planer, has cyclic $\pi$ electron cloud and complies with Hückel rule. Therefore, cyclopentadienyl anion is a relatively stable aromatic species $^{3}$. Consequently, unlike the cyclopentadienyl and radical cation, it can be easily obtained through the basis treatment. The cyclopentadienyl cation and the radical are remarkably unstable and reactive species.

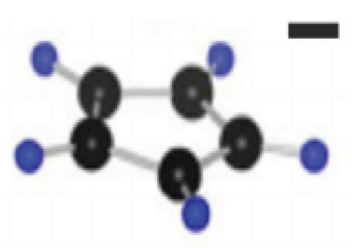

Figure 4. Cyclopentadienyl anion $\left[\mathrm{C}_{5} \mathrm{H}_{5}\right]^{-}$

In modern computation (Litofsky \& Viswanathan, 2015; Slee \& Macdougall, 1988) all the resonance integrals and overlap would be included but an indication of the molecule parameters can be obtained with the help of Hückel approximation. The difficulties arising from the severe assumptions of Hückel method have been overcome for more sophisticated theories that helpful to understanding the systems parameters (Jadhav et al., 2020) as shapes or geometries, $\pi$ energies (Atkins \& Paula, 2006), delocalization energy electron (Atkins \& Paula, 2006; Jadhav et al., 2020) and charge density (Atkins \& Paula, 2006) and consequently, to predict the stability of a cyclic molecular system (Puri, Sharma, Pathania \& Kaur, 2009; Jadhav et al., 2020).

\section{Theoretical Method}

\subsection{Formation of Cyclopentadiene System}

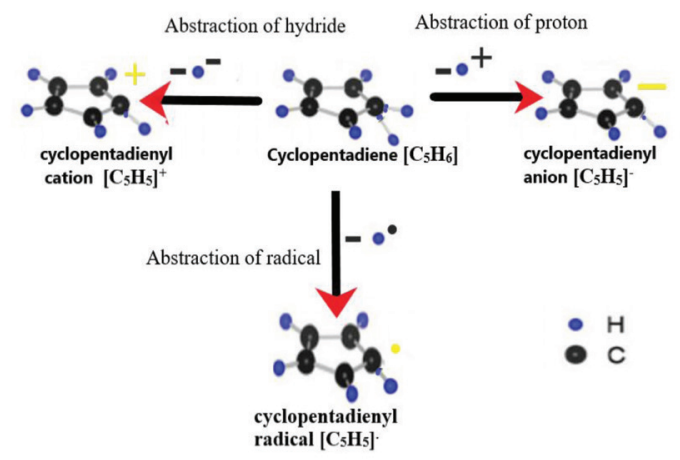

Figure 5. Cyclopentadienyl system i.e. formation of cation, anion and radical species. 


\subsection{Secular determinant for cyclopentadienyl system}

$\mathrm{C}_{5} \mathrm{H}_{5}^{+}$(cation), $\mathrm{C}_{5} \mathrm{H}_{5}^{-}$(anion), and $\mathrm{C}_{5} \mathrm{H}_{5}{ }^{-}$(radical). The number of carbon atoms is the same in three system, so the secular determinant is unchanged.

$$
\left[\begin{array}{lllll}
x & 1 & 0 & 0 & 1 \\
1 & x & 1 & 0 & 0 \\
0 & 1 & x & 1 & 0 \\
0 & 0 & 1 & x & 1 \\
1 & 0 & 0 & 1 & x
\end{array}\right]=0
$$

\subsection{Secular Equation: (unchanged for the} system)

Consider, the carbon atom $\left(\mathrm{C}_{1}\right)$, It is next to atoms $\mathrm{C}_{5}$ and $\mathrm{C}_{2}$, then the corresponding secular equation is:

$$
\mathrm{XC}_{1}+\mathrm{C}_{2}+\mathrm{C}_{5}=\mathrm{O}
$$

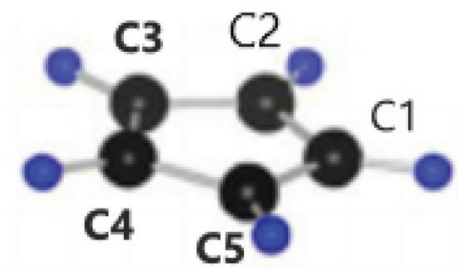

Figure 6. cyclopentadienyl system (Indicated the position of carbon atoms).

- $\quad$ Each secular equation includes 3 non-zero terms.

- All the five secular equations have the same molecular structure, and they can be obtained from each other by permuting the indices.

- It can be solved by using trigonometric functions.

- The trigonometric solutions can be represented by a simple geometric construction i.e. Circle method.

Similarly, for $\mathrm{C}_{2}, \mathrm{C}_{3}, \mathrm{C}_{4}$ and $\mathrm{C}_{5}$ the secular equation as follows,

$$
\begin{aligned}
& \mathrm{C}_{1}+\mathrm{XC}_{2}+\mathrm{C}_{3}=0, \mathrm{C}_{2}+\mathrm{XC}_{3}+\mathrm{C}_{4}=0 \\
& \mathrm{C}_{3}+\mathrm{XC}_{4}+\mathrm{C}_{5}=0, \mathrm{C}_{1}+\mathrm{C}_{4}+\mathrm{XC}_{5}=0
\end{aligned}
$$

\subsection{X values: (Unchanged for the system)}

The $\mathrm{X}$ values can be obtained by solving the secular determinant, $\mathrm{X}_{1}=-2.000, \mathrm{X}_{2}=-0.618, \mathrm{X}_{3}=-0.618$, $\mathrm{X}_{4}=1.618, \mathrm{X}_{5}=1.618$. Energy levels, $X=\frac{\alpha-E}{\beta}$

\subsection{Total $\pi$ energy}

$$
E_{\pi}=\sum n_{i} \mathrm{E}_{\mathrm{i}}=\mathrm{n}_{1} \mathrm{E}_{1}+\mathrm{n}_{2} \mathrm{E}_{2}+\mathrm{n}_{3} \mathrm{E}_{3}+\mathrm{n}_{4} \mathrm{E}_{4}+\mathrm{n}_{5} \mathrm{E}_{5}
$$

Where, $\mathrm{n}_{\mathrm{i}}=$ number of electrons in the $\mathrm{i}^{\text {th }}$ energy state. $E_{i}=i^{\text {th }}$ energy equation or value.

\subsection{Delocalization energy (DE)}

D.E $=(\pi$ electron energy of the system $)-(\pi$ electron energy of an equivalent number of isolated double bonds).

An odd number of carbon atoms in a conjugated system then the comparison energy is taken to be that of an equivalent number of isolated double bonds plus alpha for the energy of the odd electron.

\subsection{Wave functions}

The general wave function equation as,

$$
\Psi_{\mathrm{i}}=\mathrm{a}_{1} \mathrm{P}_{1}+\mathrm{a}_{2} \mathrm{P}_{2}+\mathrm{a}_{3} \mathrm{P}_{3}+\mathrm{a}_{4} \mathrm{P}_{4}+\mathrm{a}_{5} \mathrm{P}_{5}
$$

Solving the wave functions for the cyclopentadienyl system in terms of coefficients (a) by using the normalized and orthogonalized condition as

$$
\int \psi_{i} \Psi_{j} \mathrm{dX}=1 \text {----- }(\mathrm{i}=\mathrm{j}, \text { normalized condition })
$$

$\int \psi_{i} \Psi_{\mathrm{j}} \mathrm{dX}=0$------ $(\mathrm{i} \neq \mathrm{j}$, orthogonalized condition $)$

The wave function for the system as,

$$
\begin{aligned}
& \Psi_{1}=\frac{1}{\sqrt{5}}\left(\mathrm{P}_{1}+\mathrm{P}_{2}+\mathrm{P}_{3}+\mathrm{P}_{4}+\mathrm{P}_{5}\right) \\
& \Psi_{2}=-0.51 \mathrm{P}_{1}+0.63 \mathrm{P}_{2}-0.51 \mathrm{P}_{3}+0.20 \mathrm{P}_{4}+0.20 \mathrm{P}_{5} \\
& \Psi_{3}=-0.3717 \mathrm{P}_{1}+0.3717 \mathrm{P}_{3}+0.6015 \mathrm{P}_{4}+0.6015 \mathrm{P}_{5} \\
& \Psi_{4}=-0.21 \mathrm{P}_{1}-0.63 \mathrm{P}_{2}-0.20 \mathrm{P}_{3}+0.51 \mathrm{P}_{4}+0.51 \mathrm{P}_{5} \\
& \Psi_{5}=0.6015 \mathrm{P}_{1}-0.6015 \mathrm{P}_{3}+0.3717 \mathrm{P}_{4}+0.3717 \mathrm{P}_{5}
\end{aligned}
$$

\subsection{Electron Density}

The total electron density at an atom $r$ is defined as the sum of electron densities contributed by different electrons in each HMO as,

Electron Density $\left(\mathrm{q}_{\mathrm{r}}\right)=\underline{\varepsilon} \mathrm{n}_{\mathrm{i}} \mathrm{a}_{\mathrm{i}}^{2}$

Where, $a_{i}$ is the coefficients of the atom $r$ in the $i^{\text {th }}$ HMO and $n_{i}$ is the number of electrons in that HMO. (values of $\mathrm{n}=0,1$, or 2 ). 


\subsection{Charge Density}

In the $\pi$ system, a neutral carbon is associated with an electron density of 1.0 and so the net charge density is defined by the equation, Charge density $=1-\mathrm{q}_{\mathrm{r}}$

\section{Results and Discussion}

In a conjugated cyclic system, the $\pi$ electrons are delocalized over the entire cyclic system and even the single bonds part takes of the double bond character, even at only presence of delocalized electrons in a system. The molecular parameters as follows which is solved by using Hückel approximation theory,

\subsection{Total $\pi$ energy}

\section{- $\left[\mathrm{C}_{5} \mathbf{H}_{5}\right]^{+}$cation:}

$E_{\pi}=2(\alpha+2 \beta)+2(\alpha+0.618 \beta)$

$=4 \alpha+5.296 \beta$

\section{- $\left[\mathrm{C}_{5} \mathbf{H}_{5}\right]$ Radical:}

$E_{\pi}=2(\alpha+2 \beta)+3(\alpha+0.618 \beta)$

$$
=5 \alpha+5.854 \beta
$$

\section{- $\left[\mathbf{C}_{5} \mathbf{H}_{5}\right]^{-}$anion:}

$E_{\pi}=2(\alpha+2 \beta)+4(\alpha+0.618 \beta)$

$$
=6 \alpha+6.472 \beta
$$

According to the value of total $\pi$ energy of a system in which anion species shows high energy indicates more stability.

\subsection{Delocalization energy $(D E)$}

- $\left[\mathrm{C}_{5} \mathbf{H}_{5}\right]^{+}$cation:

$E_{\mathrm{DE}}=4 \alpha+5.296 \beta-\{2(\alpha+\beta)+2(\alpha+0.618 \beta)\}$ $=2 \beta$

- $\left[\mathrm{C}_{5} \mathrm{H}_{5}\right]$ Radical:

$E_{\mathrm{DE}}=4 \alpha+5.854 \beta-\{2(\alpha+\beta)+3(\alpha+0.618 \beta)\}=2 \beta$

- $\left[\mathbf{C}_{5} \mathbf{H}_{5}\right]^{-}$anion:

$E_{\mathrm{DE}}=6 \alpha+6.472 \beta-\{2(\alpha+\beta)+4(\alpha+0.618 \beta)\}=2 \beta$

The delocalization energy of a cyclopentadienyl system remains unchanged.

\subsection{Electron and charge density}

- $\left[\mathbf{C}_{5} \mathbf{H}_{5}\right]^{+}$cation:

Electron Density $\left(\mathrm{q}_{\mathrm{r}}\right)$,

at $\mathrm{C}_{1}, \mathrm{q}_{\mathrm{r}}=\mathrm{n}_{1} \mathrm{a}_{1}^{2}+\mathrm{n}_{2} \mathrm{a}_{2}^{2}$

$$
=2 \times\left(\frac{1}{\sqrt{5}}\right)^{2}+2 \times\left(\frac{1}{\sqrt{5}}\right)^{2}=0.800
$$

at $\mathrm{C}_{2}, \mathrm{q}_{\mathrm{r}}=\mathrm{n}_{1} \mathrm{a}_{1}^{2}+\mathrm{n}_{2} \mathrm{a}_{2}^{2}$

$$
=2 \times(-0.51)^{2}+2 \times(0.63)^{2}=1.314
$$

at $C_{3}, q_{r}=n_{1} a_{1}^{2}+n_{2} a_{2}^{2}$

$$
\begin{aligned}
& =2 \times(-0.3717)^{2}+2 \times(0.3717)^{2}=0.552 \\
\text { at } \mathrm{C}_{4}, \mathrm{q}_{\mathrm{r}} & =\mathrm{n}_{1} \mathrm{a}_{1}{ }^{2}+\mathrm{n}_{2} \mathrm{a}_{2}{ }^{2} \\
& =2 \times(-0.21)^{2}+2 \times(-0.63)^{2}=0.8820 \\
\text { at } \mathrm{C}_{5}, \mathrm{q}_{\mathrm{r}}= & \mathrm{n}_{1} \mathrm{a}_{1}{ }^{2}+\mathrm{n}_{2} \mathrm{a}_{2}{ }^{2} \\
& =2 \times(0.6015)^{2}+2 \times(-0.6015)^{2}=1.447
\end{aligned}
$$

Charge density $=1-\mathrm{q}_{\mathrm{r}}$ At, $C_{1}=0.200, C_{2}=-0.314, C_{3}=0.4474$,

$\mathrm{C}_{4}=0.118, \mathrm{C}_{5}=-0.4472$

- $\left[\mathrm{C}_{5} \mathrm{H}_{5}\right]$ Radical:

Electron Density $\left(\mathrm{q}_{\mathrm{r}}\right)$,

at $\mathrm{C}_{1}, \mathrm{q}_{\mathrm{r}}=\mathrm{n}_{1} \mathrm{a}_{1}^{2}+\mathrm{n}_{2} \mathrm{a}_{2}^{2}$

$$
\begin{aligned}
& =2 \times\left(\frac{1}{\sqrt{5}}\right)^{2}+2 \times\left(\frac{1}{\sqrt{5}}\right)^{2}+1 \times\left(\frac{1}{\sqrt{5}}\right)^{2} \\
& =1.000 \\
\text { at } \mathrm{C}_{2}, \mathrm{q}_{\mathrm{r}} & =\mathrm{n}_{1} \mathrm{a}_{1}^{2}+\mathrm{n}_{2} \mathrm{a}_{2}^{2}+\mathrm{n}_{3} \mathrm{a}_{3}^{2} \\
& =2 \times(-0.51)^{2}+2 \times(0.63)^{2}+1 \times(-0.51)^{2} \\
& =1.5741 \\
\text { at } \mathrm{C}_{3}, \mathrm{q}_{\mathrm{r}} & =\mathrm{n}_{1} \mathrm{a}_{1}^{2}+\mathrm{n}_{2} \mathrm{a}_{2}^{2}+\mathrm{n}_{3} \mathrm{a}_{3}^{2} \\
& =2 \times(-0.3717)^{2}+2 \times(0.3717)^{2}+(0.6015)^{2} \\
& =0.9144 \\
\text { at } \mathrm{C}_{4}, \mathrm{q}_{\mathrm{r}} & =\mathrm{n}_{1} \mathrm{a}_{1}^{2}+\mathrm{n}_{2} \mathrm{a}_{2}^{2}+\mathrm{n}_{3} \mathrm{a}_{3}^{2} \\
& =2 \times(-0.21)^{2}+2 \times(-0.63)^{2}+1 \times(-0.20)^{2} \\
& =0.922 \\
\text { at } \mathrm{C}_{5,} \mathrm{q}_{\mathrm{r}} & =\mathrm{n}_{1} \mathrm{a}_{1}^{2}+\mathrm{n}_{2} \mathrm{a}_{2}{ }^{2}+\mathrm{n}_{3} \mathrm{a}_{3}^{2} \\
& =2 \times(0.6015)^{2}+2 \times(0.6015)^{2}+(0.3717)^{2} \\
& =1.585
\end{aligned}
$$

Charge density $=1-\mathrm{q}_{\mathrm{r}}$

At, $\mathrm{C}_{1}=0.00, \mathrm{C}_{2}=-0.5741, \mathrm{C}_{3}=0.0856$,

$\mathrm{C}_{4}=0.078, \mathrm{C}_{5}=-0.5853$

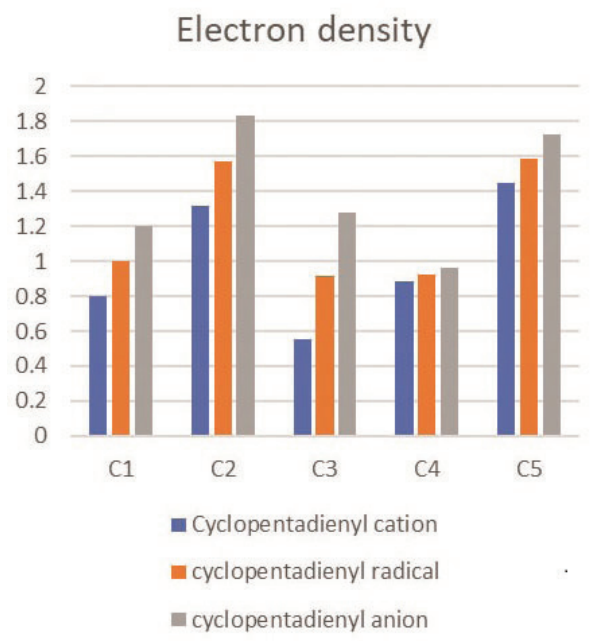

Figure 7: Graphical method of electron density for cyclopentadienyl system. 
- $\left[\mathrm{C}_{5} \mathbf{H}_{5}\right]^{-}$(Anion):

Electron Density $\left(\mathrm{q}_{\mathrm{r}}\right)$

$$
\begin{aligned}
& \text { at } \begin{aligned}
\mathrm{C}_{1}, \mathrm{q}_{\mathrm{r}} & =\mathrm{n}_{1} \mathrm{a}_{1}^{2}+\mathrm{n}_{2} \mathrm{a}_{2}^{2} \\
& =2 \times\left(\frac{1}{\sqrt{5}}\right)^{2}+2 \times\left(\frac{1}{\sqrt{5}}\right)^{2}+2 \times\left(\frac{1}{\sqrt{5}}\right)^{2} \\
& =1.200 \\
\text { at } \mathrm{C}_{2}, \mathrm{q}_{\mathrm{r}} & =\mathrm{n}_{1} \mathrm{a}_{1}^{2}+\mathrm{n}_{2} \mathrm{a}_{2}^{2}+\mathrm{n}_{3} \mathrm{a}_{3}^{2} \\
& =2(-0.51)^{2}+2(0.63)^{2}+2(-0.51)^{2} \\
& =1.834 \\
\text { at } \mathrm{C}_{3}, \mathrm{q}_{\mathrm{r}} & =\mathrm{n}_{1} \mathrm{a}_{1}^{2}+\mathrm{n}_{2} \mathrm{a}_{2}^{2}+\mathrm{n}_{3} \mathrm{a}_{3}^{2} \\
& =2(-0.3717)^{2}+2(0.3717)^{2}+2(0.601)^{2} \\
& =1.276 \\
\text { at } \mathrm{C}_{4}, \mathrm{q}_{\mathrm{r}} & =\mathrm{n}_{1} \mathrm{a}_{1}^{2}+\mathrm{n}_{2} \mathrm{a}_{2}^{2}+\mathrm{n}_{3} \mathrm{a}_{3}^{2} \\
& =2(-0.21)^{2}+2(-0.63)^{2}+2(-0.20)^{2} \\
& =0.962 \\
\text { at } \mathrm{C}_{5,}, \mathrm{q}_{\mathrm{r}} & =\mathrm{n}_{1} \mathrm{a}_{1}^{2}+\mathrm{n}_{2} \mathrm{a}_{2}^{2}+\mathrm{n}_{3} \mathrm{a}_{3}^{2} \\
& =2(0.6015)^{2}+2(0.6015)^{2}+2(0.3717)^{2} \\
& =1.723
\end{aligned}
\end{aligned}
$$

Charge density $=1-\mathrm{q}_{\mathrm{r}}$

At, $\mathrm{C}_{1}=-0.200, \mathrm{C}_{2}=-0.8342, \mathrm{C}_{3}=-0.2762$,

$\mathrm{C}_{4}=0.038, \mathrm{C}_{5}=-0.7235$

\section{Conclusion}

This study has obtained theoretical results on the cyclopentadienyl system i.e. $\mathrm{C}_{5} \mathrm{H}_{5}^{+}, \mathrm{C}_{5} \mathrm{H}_{5}^{-}$and $\mathrm{C}_{5} \mathrm{H}_{5}$, Which gives the same delocalization energy $(2 \beta)$ in terms of a system, the pi energy of a system is different, its shows that cyclopentadienyl anion is more stable, the stability trend as, $\mathrm{C}_{5} \mathrm{H}_{5}^{+}$(cation, antiaromatic) < $\mathrm{C}_{5} \mathrm{H}_{5} \cdot$ (radical, nonaromatic) $<\mathrm{C}_{5} \mathrm{H}_{5}^{-}$(anion, aromatic). It also shows that the electron and charge density can yield electronic properties, the graphical method as shown in Figure 7, indicates that high electron density of cyclopentadienyl anion at each carbon atom, it is representation of the probability of finding electron more around the carbon atoms. Consequently, students easily get idea about the molecular parameters of the cyclopentadienyl system.

\section{Acknowledgements}

I would like to thankful to Prof (Dr) R. D. Darekar, Prof B. S. Shinde (HOD, Chemistry Dept), Prof Arun M. Bhagare and Dr Akshay Dhaygude, who always supported and encourage for this work.

\section{References}

Atkins, P. \& Paula, J. de (2006). Physical Chemistry. Eight Edition, Oxford University Press.

Breton, G.W. (1997). Generation and Observation of the Cyclopentadienyl Anion: A Negatively Charged Aromatic Molecule. Chem. Educator, 2, 1-8. https://doi.org/10.1007/s00897970152a

Chalyavi, N., et al. (2013). Electronic Spectroscopy of the 1,3-Cyclopentadiene Cation $(\mathrm{C} 5 \mathrm{H}+6)$. J. Phys. Chem. A, 117(44), 11276-11281. https://doi.org/10.1021/ jp408449e

Freeman, F. (1980). Hückel molecular orbital theory (Yates, Keith). J. Chem. Educ., 57(10), A296. https://doi. org/10.1021/ed057pA296.3

Freeman, W.P., Tilley, T.D., Liable-Sands, L.M. \& Rheingold, A.L. (1996). Synthesis and Study of Cyclic $\pi$-Systems Containing Silicon and Germanium. The Question of Aromaticity in Cyclopentadienyl Analogues. J. Am. Chem. Soc., 118(43), 10457-10468. https://doi.org/10.1021/ja962103g

Jadhav, V.R. (2018). Straightforward Numerical Method to Understanding the Valence Shell Electron Pair Theory (VSEPR). International Journal of Research \& Review, 5(9), 10-13.

Jadhav, V.R., et al. (2020). Theoretical Approach to Understanding an Electron Density, Charge Density and Most Stable Configuration of H3 System. International Journal of Research and Review, 7(3), 477-480.

Litofsky, J. \& Viswanathan, R. (2015). Introduction to Computational Chemistry: Teaching Hückel Molecular Orbital Theory Using an Excel Workbook for Matrix Diagonalization. J. Chem. Educ., 92(2), 291-295. https://doi.org/10.1021/ed500376q

Puri, B.R., Sharma, L.R., Pathania, M.S. \& Kaur, N. (2009). Chapter 2. Chemical bonding: molecular quantum mechanics. Principle of Fundamentals of physical chemistry, 131-195.

Sayfutyarova, E.R. \& Hammes-Schiffer, S. (2019). Constructing molecular $\pi$-orbital active spaces for multireference calculations of conjugated systems. Journal of chemical theory and computation, 15(3), 1679-1689. https://doi.org/10.1021/acs.jctc.8b01196

Slee, T.S. and Macdougall, P.J. (1988). The correspondence between Hückel theory and ab initio atomic charges in allyl ions. Canadian Journal of Chemistry, 66(11), 2961-2962. https://doi.org/10.1139/v88-459

Yates, K. (2012). Hückel molecular orbital theory. Elsevier. 
Journal of Chemistry, Environmental Sciences and its Applications

Chitkara University, Saraswati Kendra, SCO 160-161, Sector 9-C, Chandigarh, 160009, India

Volume 6, Issue 2

March 2020

ISSN 2349-7769

Copyright: [@ 2020 Vikram R. Jadhav et al.] This is an Open Access article published in Journal of Chemistry, Environmental Sciences and its Applications (J. Chem. En. Sci. A.) by Chitkara University Publications. It is published with a Creative Commons Attribution- CC-BY 4.0 International License. This license permits unrestricted use, distribution, and reproduction in any medium, provided the original author and source are credited. 